\title{
Methodology of creative work: transformation structure
}

\author{
Tatiana Eroshenko ${ }^{1 *}$, Aleksandr Fedoseenkov ${ }^{1}$, Gennadiy Sorokin ${ }^{1}$, and Aleksandr \\ Malyshev $^{1}$ \\ ${ }^{1}$ Don State Technical University, 344022, Rostov-on-Don, Russia
}

\begin{abstract}
The authors consider the phenomenon of transformation of methodological strategies of social cognition, which in theory reflects the grounds of self-preservation and self-replication of social and anthropological reality. The article underlines that at present time social cognition tools are going through a renewal that is dynamic and subject to theoretical and methodological changes. The emphasis is shifting from research of the general social level toward individuality, subjectivity, spontaneity and cultural uniqueness of fractals of social existence. They observe the danger in creation of social reality, if it is not guided by organic unity of knowledge and morality. From our point of view, morality is a systemic factor of social reality, because as high as social barriers in modern world may be, universal values do exist and preserve and they are exactly the things that give human society an opportunity to survive on a global scale.
\end{abstract}

\section{Ideological preconditions for search for a new methodology}

Dissatisfaction with the present state of the society on a global level is the reason to address the fundamental basics and historical sources of emergence of scientific knowledge about society. Modern sociality is characterized by ontological heterogeneity, spontaneity in growth of social practice types, variegation and multi-directionality of socio-cultural flows and enclaves of life experience. Dynamic character of the modern society requires a methodology relevant to these changes that is able to find appropriate strategies of sociality development and reproduction. Under the conditions of globalization of the modern society, there is a "translation" of social cognition methodologies from the language of one culture to the language of another one. Thus, research of transformation of methodological strategies of social cognition has an important regulating meaning for the whole system of the humanities and social knowledge and gives us a chance to trace the tendencies of change in the categories framework of the modern social theory.

At present, renewal of social cognition tools is dynamic in nature being subject to theoretical-methodological and ideological-political changes. In the theoretical and methodological context, changes affected the status of the social science itself; revision of

\footnotetext{
* Corresponding author: eroschenko-1970@mail.ru
} 
classical social theories and their replacement with methodologies without clear criteria of scientific content is in process now. "Soft" methods of cognition step forward, which are aimed at individuality, subjectivity, cultural style of the object under research, its unique peculiarity. The emphasis shifts from studies of general social level to personal, individual, moral and ethical phenomena that characterize the daily life of people. Academic variety of approaches and concepts often causes mess in opinions related to both social reality itself and theories and concepts that represent it, which leads to methodological eclecticism and flaunting of some ideological anarchism.

In the context of modern multipolar world, it is more than ever necessary to have clear ideals defining the goals and outlook of social development that set benchmarks of social and personal life of a person. Under these conditions, there become very popular social theories as programs of strategic development of social reality that consolidate the society and determine personal values. Modern world is unthinkable without social practices that change different layers of social life on the basis of programs that one way or another interfere in peoples' life, changing conditions of existence of different social communities.

In foreign and domestic scientific literature, there is a significant number of published works relating to the specific nature of social knowledge, its transformation and status in the society. These issues are considered both from the position of different disciplines (in studies on social philosophy, political science, history, sociology, social ecology, psychology, philosophy of science, science studies) and as a whole.

Already in the 19th century, Western researches such as A. Comte, H. Spencer, K. Marx, E. Durkheim, M. Weber tried to gain an insight in the society, discover the laws of creation and development of social reality; they did a great amount of work on genealogy of the social [A. Comte 2003, K. Marx 1955-1981, M. Weber 1990, E. Durkheim 1995, H. Spencer 2013].

From the very emergence of the science about society, there arose a question about interrelation between scientific and socio-humanitarian methodological approaches in scientific research, which turned into identification of peculiarity of sciences about the world of nature and sciences about the human world, i.e. "sciences about spirit". The problem was first brought to the philosophical and methodological level by W. Dilthey, who paid attention to the peculiarity of the subject of the social and humanitarian cognition [Dilthey W., 1987]. His ideas about the peculiarity of social and humanitarian methodology were supported and developed by H. Rickert, H.G. Gadamer, K. Popper [H. Rickert 1913, H.G. Gadamer 1991, K. Popper 1993]. A special place is taken by the problem of interrelation between values and knowledge stated by the founders of the Baden School of Neo-Kantianism W. Windelband and H. Rickert that was further developed in works by M. Weber. Today, the problem of value-based conditioning of human existence under the paradigm of social and humanitarian knowledge is studied by contemporary Russian philosophers [L. Mikeshina, 2002, V. Kuznetsov 1991, V. Stepin 2000, A. Rutkevich 2018, A. Antonovskiy 2018] etc. The peculiarity of social reality cognition in the context of moral-ethical and religious problems was reflected in the works of Russian philosophers of the 19th - 20th centuries [V. Solovyev 1988, N. Berdyaev 1994, V. Vernadskiy 1983, P. Sorokin 2009].

One should note the importance of research in the sphere of social and anthropological synergetics, which considers the process of emergence of self-organizing social structures out of disorder and chaos, non-linearity of social systems and their fractality, causes of structural genesis of social and anthropological reality as a complicated historically selforganizing system [V. Arshinov, 2011, E. Knyazev and S. Kurdyumov 2005, S. Khoruzhiy, 2011, I. Prigozhin 1991].

Interest in the action of synergistic mechanisms is noticeably growing. Societies that seemed to be solid and powerful quickly fall into relatively independent enclaves, 
subsystems, temporary dissipative structures. In brief, social reality is understood as unstable, discrete and multifarious. Therefore, there always arises a need in the society for new ways of social reality presentation, consideration and study of methodologies showing the prospects of social and cultural development. This attitude is associated with the vision of social reality as a very complicated and specific thing in relation to the natural reality. So, there become actual the methodologies that pay attention not only to official discourse, but also to narratives about regular practices that draw attention to the fact that society is integrated not only by institutional links.

The most important theoretical component of research of social methodology development is represented by the ways of presentation of social programs of person's and society life activity that have ideological content and are realized in supreme values of social life.

Availability of literature dedicated to different aspects of methodology of social knowledge does not solve the problem of a lack of studies specifically devoted to the transformation of social methodology as an ideology of social reality design. Currently, there is no developed toolset of the social science itself, setting values for the subject of cognition and properly reflecting changes in social transformations in the world system as a whole.

The objective of the research is to present a social and philosophical analysis of transformation of methodological strategies of social reality cognition in accordance with the stages of science development in modern and contemporary times, their transposition into ideological systems with the further realization in social experience.

\section{Significant changes in organizational basics of science}

A peculiar feature of modern knowledge about society is its sharp subject, methodological and worldview differentiation that shows itself in coexistence of numerous schools and areas in scientific cognition of the society, as well as the problematization of daily routine in social cognition. At the same time, pluralism stimulates the search for a common basis for describing and justifying the integration of isolated knowledge about society and its historical transformation. This search aims at discovery of the hidden nature and inner connection of diverse, opposing and conflicting schools that make up a mosaic of social science. Historical interpretation of the methodology is aimed at finding sustainable forms and social and cultural conditions of their evolution and renewal. Changes in society result in changes in methodological strategies related to presentation of social reality itself. Moreover, under modern conditions the scientific methodology that formed in the GalileoNewton-Descartes age loses its indisputability.

Modern Russian researchers deal not only with the concept of paradigm but also with the concept of metaparadigm, which means paradigms and theories in reference to each other. In sociology, a metaparadigm means a systematic concept of interrelations between different theories. For example, three main metaparadigms in sociology are the following: classical, postclassical i.e. modernism, post-postclassical meaning science of our time. The main criterion of metaparadigm identification is a certain scientific worldview [V. Yadov 2006. 11]. The idea of change of sociological metaparadigms on the basis of the stages of science development belongs to P. Sztompka, who notes that the goal of this or that new metaparadigm is to abandon the obsolete worldview and idea of the society and to bring the sociological theory into line with the new image of the science [P. Sztompka 1996. 9].

We use the concept of "methodological strategies", which are, in our opinion, the basics for creation of forms and ways of cognition, including elements of implicit knowledge, art, foreknowledge, intuition etc. Today, a growing number of philosophers and methodologists come to a conclusion that violation of borders of scientific area, introduction of irrational 
moments in science should be considered as an attempt to overcome the state of intellectual gap, an attempt to enhance intuitive and non-logical abilities of human thinking that works close to the natural border of its abilities. At later stages of social cognition development, many of these theoretic ideas can be rationalized. In the basis of traditional ideas about knowledge, there are such functional elements as theories, hypotheses and methods. They make it possible to eliminate externally in full everything that is to some extent connected with the actor and sociocultural parameters of his activity. In a new cognitive situation, we mean such units of social knowledge measurement as text, scenario or frame, scheme, situational pattern that came from linguistics and then got a new meaning in the artificial intelligence programs [L. Mikeshina 1997. 108].

Methodological framework of the paper is formed by the philosophical method of ascending from the abstract to the concrete, general humanitarian methods such as: historical method, method of comparison, analysis and synthesis method. Theoretical basis is a philosophical review of the social phenomenon of transformation of methodological strategies of social cognition (TMSSC) related to conceptual toolset of the system and synergetic approach. Basing on the ideas of domestic researchers E. Knyazeva and S. Kurdyumov, T. Eroshenko [E. Knyazeva and S. Kurdyumov, 2005, T. Eroshenko 2017], we consider TMSSC as complicated processes reflecting dynamics of self-organization, self-development or self-creation of societies.

\section{Basic principles of transformation}

The conducted research allows us make the following conclusions:

1. Dissatisfaction with the present state of social sciences is one of the reasons to address the fundamental basics and historical sources of formation of scientific knowledge about society and transformation of their methodological strategies. Social sciences have their sources in ancient times, in accumulating knowledge about society, person and his behaviour. The systematization of this kind of knowledge has long been taking place within the framework of religious studies and social and philosophical schemes. The science about society was established only in the 19th century, when in industrial civilization there formed an attitude to various social phenomena as objects of control and transformation and the need to carry out control of social reality was recognized.

2. Social sciences that have taken shape in the era of formation and development of technogenic culture have gone through approval and justification of specific methodology that offers a person a certain worldview and forms his way of thinking in the same way making the basis for fundamental postulates of ideology. The very pragmatics of ideology practice encourages social sciences to develop explanatory schemes of the society in the form of ideas and concepts in order to introduce them into the public consciousness.

3. Indirectly through educational channels and social media, social science acts as a specific system of standards of behaviour because it creates ideology by means of the scheme of "messages" that transpose the language of social science to the language of its mass consumption. Acceptance of some concepts of social science as an ideology can be considered as a real success. Influence of the ideological struggle on the processes of selfrealization and self-destruction of the society has rapidly grown.

4. Complexity of social objects is intensifying; interrelations between them become more and more syncretic. At the same time, they are social, ecological, economic, political, ethical ones. Importance of the ecological component of social relations is dramatically increasing; it covers and controls all the rest components. New concepts describing social phenomena require regular adjustment.

5. Methodological strategies, being the guides of social reality design, at the same time contain ideological implications; any social theory is inspired by intention to get into 
programming of reality, while carrying out social design. Main characteristics of transformation of social methodology as an ideology of social design are the following: extent of representation of structural complexity of social reality; place and role of the actor in cognition and design of social reality; methodological unity of abstract-theoretical and actual-practical sides; methodological interrelation of theorism and narrative; methodological strategies of society cognition are considered as a product of cultural and historical evolution of the society itself; valuable contribution of the social cognition methodology into social development as a whole is specified. Ideological constructs created by strategies of social cognition present a whole subsystem of the spiritual life of society, value configurations that somehow form, as well as hierarchy of standard structures.

6. In organizational basics of social sciences at the end of the 20th - beginning of the 21 st centuries, significant changes have occurred that include teaching of the humanities and social sciences as one of the channels of advocacy of ideological and ethical knowledge, the importance of which is growing. Unfortunately, nowadays in schools and universities there is a tendency for decrease of interpersonal communication and increase of mechanization of human interaction in the educational system. This moves teaching of the humanities and social sciences closer to the model that combines features of the model either neutral from the axiological point of view, or dysfunctional from the social and anthropological point of view. Strengthening and spread of this tendency reflects deethication and de-greening as immanent processes leading to society degradation as a whole.

Nowadays, non-conformism becomes a lifestyle of the whole groups, communities, societies. It keeps shaking the societies. There can be one step from a stupid thing to a serious drama, if you react to it inappropriately. In modern processes of globalization, we can increasingly state the fact that social structures depend on individual mentality of a person, on view of life, spiritual processes running in the person's consciousness and mind, as a result, social reality always changes. These changes are reflected in the transformation of methodological strategies of its presentation. A philosophical analysis of the transformation of methodological strategies in social cognition allows us to answer the question: what stimulates new methodologies of society cognition and how they are used for presentation of social reality, its simulation and prediction, being the ideologies of social practice.

The main characteristics of the transformation of social methodology as an ideology of social design are the following: extent of representation of structural complexity of social reality; place and role of the actor in cognition and design of social reality; methodological unity of abstract-theoretical and actual-practical sides; methodological interrelation of theorism and narrative; methodological strategies of society cognition are considered as a product of cultural and historical evolution of the society itself; valuable contribution of the social cognition methodology into social development as a whole is specified.

\section{Conclusion}

Thus, we should emphasize the unity of moral and scientific sides as a fundamental base of knowledge nowadays, significance and special role of methodological efforts of the humanities. Scientific knowledge sets the key parameters of order and stabilization of development of the social and cultural space through acculturation of the moral element of a certain person. Modern efficient system of personal ethical and moral socialization is possible in cooperation and interrelation of different types of spirituality that are communicated by the humanitarian element of social mentality as an axiological principle realized in an individual person and different cultural communities. It is necessary to identify and accept the religious and imaginative element of secular scientific knowledge. 
Evolution of the main preceding, operating and developing strategies has determined and determines the worldview paradigms of social cognition of classical, non-classical and post-non-classical science. This evolution changed the content of the main political western ideologies - liberal, socialist and conservative one - beyond recognition. We should emphasize that the forming post-non-classical paradigm as a methodology and ideology of "social creativity" kind of pushes researches to deeper understanding and acceptance of Socrates's idea of unity of knowledge and morality. This commitment to the unity of knowledge as the truth and morality, as the public good to some extent became characteristic of all important social and philosophical schools.

\section{References}

1. A. Comte, The Spirit of Positive Philosophy (Rostov-on-Don, 2003)

2. K. Marx, F. Engels, 2nd edition, 1-50 (Moscow, 1955-1981)

3. M. Weber, Selected Works (Moscow, 1990)

4. E. Durkheim, Sociology. Its Subject, Method, Purpose (Moscow, 1995)

5. H. Spencer, Social Statistics (Gama-Print, K., 2013)

6. W. Dilthey, Introduction to Sciences about Spirit/ (Foreign Aesthetics and Theory of Literature of the 19th - 20th centuries, Treatises, articles, essays. Moscow,1987)

7. H. Rickert, Two Ways in Cognitive Theory. New ideas in philosophy (Sb.7-SPB., 1913).

8. H. Gadamer, Truth and Method (Moscow, 1988).

9. K. Popper, The Poverty of Historicism ("Progress" Moscow, 1993)

10. V. Solovyev, Two-book set (Moscow, 1988)

11. N. Berdyaev, Philosophy of Free Spirit (Moscow, 1994)

12. V. Vernadskiy, Scientific Thought as a Planetary Phenomenon (Philosophical ideas of a naturalist, Moscow, 1983)

13. P. Sorokin, Crisis of Our Age. Social and Cultural Review (ISPI RAN, Moscow,2009)

14. P. Sztompka, The Sociology of Social Changes (Moscow, 1996)

15. L. Mikeshina, Philosophy of Cognition: Polemic Chapters ( Moscow, 2002)

16. L. Mikeshina, M. Openkov, New Images of Cognition and Reality (Moscow, 1997))

17. V.G. Kuznetsov, Hermeneutics and Humanitarian Cognition (Moscow, 1991)

18. V. Stepin, Theoretical Knowledge (Moscow, 2000)

19. A. Rutkevich, Historicism and Its Critics, Voprosy Filosofii, 12, (2018).

20. A. Antonovskiy, Scientific Cognition as a Concept of Social Philosophy, Voprosy Filosofii, 12, (2018).

21. V. Arshinov, Synergetics Converges with Difficulty..., Voprosy Filosofii, 4 (2011).

22. E. Knyazeva, S. Kurdyumov, Bases of Synergetics (KomKniga/URSS, Moscow, 2005)

23. S. Khoruzhiy, What is SYNERGEIA? Synergy as a Universal Paradigm: Key Domains, Discursive Links, Heuristic Resources, Voprosy Filosofii, 12, (2011).

24. I. Prigozhin, I. Stengers, Order out of Chaos (Moscow, 1986)

25. T. Eroshenko, Fractals of Social and Anthropologic Area (Essays on the theory of modelling of morphological and spiritual factors of the social, Rostov-on-Don, 2017). 
26. V. Yadov, Modern Theoretical Sociology as a Conceptual Base of Russian Transformations (St. Petersburg, 2006) 